\title{
The influence of personal tobacco smoking on the clinical practice of Italian chest physicians
}

\author{
S. Nardini*, R. Bertoletti+, V. Rastelli+, C.F. Donner ${ }^{\ddagger}$
}

The influence of personal tobacco smoking on the clinical practice of Italian chest physicians. S. Nardini, R. Bertoletti, V. Rastelli, C.F. Donner. (OERS Journals Ltd 1998.

ABSTRACT: Tobacco smoking (TS) is a major cause of lung diseases. This study aimed to determine: 1) the prevalence of TS among chest physicians; 2) the influence of the personal smoking habit on clinical practice; and 3) what training about tobacco-related issues (TI) doctors received in medical school.

A total of 983 attendees at the National Meeting of the Italian National Thoracic Society (AIPO) received a questionnaire about TI, which also contained the Fagerstroem Tolerance Questionnaire, and $605(61.5 \%)$ answered. An independent assessment of the prevalence of smokers was carried out to minimize the bias of self-selection.

The numbers of smokers was $151(25 \%)$, never-smokers $246(40.7 \%)$ and exsmokers $208(34.4 \%)$. Smoking chest physicians underestimate the health hazards of smoking $(p<0.001)$ and disregard their educational role $(p=0.005)$ more than nonsmoking chest physicians. Compliance with smoking restrictions inside hospitals is frequently poor (30.1\% smoke in clinics). In $33.1 \%$ of smokers a high nicotine addiction was found, which influenced their behaviour in hospital but not their ability to cope with tobacco-related problems. This ability was generally low: $39.1 \%$ of responders reported no training about $T I$.

Smoking is frequent among Italian chest physicians, who are poorly trained about the health effects of tobacco smoking and are poorly skilled in treating smokers. Eur Respir J 1998; 12: 1450-1453.
*Pneumophysiology Unit, Civic Hospital, Vittorio Veneto, Italy. +Pulmonary Rehabilitation Unit, "Morelli" Hospital, Sondalo, Italy. $\star$ Division of Pulmonary Disease, "S. Maugeri" Foundation, IRCCS Rehabilitation Institute of Veruno, Italy.

Correspondence: S. Nardini

Pneumotisiologia

Ospedale Civile

Via Forlanini 71

31029 Vittorio Veneto (TV)

Italy

Fax: 390438567354

Keywords: Clinical practice

nicotine addiction

tobacco smoking

Received: September 21997

Accepted after revision August 61998
Tobacco smoke causes various types of pulmonary disease. It has been calculated that $83-92 \%$ of all lung cancers among males and 57-80\% among females are caused by tobacco smoke [1-5]. Cigarette smoking is the dominant risk factor for chronic obstructive pulmonary disease (COPD) and it decreases the effectiveness of respiratory defenses, so becoming a risk factor for other infectious and noninfectious respiratory diseases.

In Italy, respiratory disease is the third greatest cause of mortality, after heart disease and cancer, but it becomes the second when lung cancers are grouped together with acute and chronic pulmonary disease.

The total number of deaths per year in Italy amounts to some 550,000 and one in six deaths is caused by tobacco [6]. The majority of these deaths are due to respiratory disease (including lung cancer). This is why chest physicians should be personally well informed about smokingrelated diseases and become leaders in the fight against smoking.

Previous reports conducted on samples of Italian physicians (not only chest physicians), showed that they underestimate the effects of tobacco smoke on health [7] and that their attitude toward smoking influences their practice [8]. It has also been reported in the past that the prevalence of smokers among Italian physicians [9] is higher than in the general population $[9,10]$.

No large study has been carried out on chest physicians. In this study the following questions were analysed. 1)
What is the prevalence of smokers and former smokers among Italian chest physicians and how do these data compare with existing data about smoking habits among other physicians and health staff in Italy? 2) What influence does the habit of cigarette smoking have on everyday clinical practice and, in the subset of smokers, what is the influence of the degree of smoking (i.e. heavy smokers versus light smokers)? 3) To what extent has formal medical teaching about tobacco smoke during university contributed to training physicians about tobacco-related disease?

\section{Methods}

The Italian Association of Hospital Chest Physicians (AIPO) has some 3,000 hospital-based members, one-third of whom normally attend the National Meeting. At the 1995 Meeting every person attending received a self-administered anonymous questionnaire about tobacco smoking. The first section of the questionnaire was concerned with demographic information. The second section asked questions about the influence of smoking on mortality compared with air pollution and occupational exposure; information about medical training as regards tobacco smoking was also sought. In addition, questions were asked about the personal attitude to and compliance with rules aimed at forbidding smoking on health premises and about the personal opinion regarding the educational role of medical 
staff, as perceived by the public at large. The third section was only for smokers and consisted of the Fagerstroem Tolerance Questionnaire (FTQ) [11] plus some additional enquiries about active and passive smoking in hospital. The fourth and final section was only for neversmokers and exsmokers and mirrored the questions put to smokers (except for the dependence test) about active and passive smoking, in Section 3. A total of 605 valid questionnaires was collected $(61.5 \%$ of the 983 attending hospital-based chest physicians).

Analysis was carried out by means of the Chi-squared and Student's t-tests, where appropriate, with $\mathrm{p}<0.05$ considered statistically significant. In one instance, analysis of variance (ANOVA) was carried out. On the basis of the FTQ, smokers were divided into high-addicted (FTQ score S5) and low-addicted (FTQ score <5) [11]. In order to prevent or minimize the bias caused if answers to the questionnaire were given preferentially by neversmokers or exsmokers, a second independent method of measuring the prevalence of smokers among attendants was carried out. In Italy, most participants at scientific meetings require a certificate of attendance, for administrative reasons. Therefore, the organizing secretariat of the meeting routinely asked each participant if he or she was a smoker or nonsmoker (and registered the response) at the moment of issuing the certificate.

\section{Results}

The results are summarized in tables 1 and 2. Data are reported as arithmetic mean \pm SD.

\section{Demographics}

The sample was composed mainly of males (113 $(18.6 \%)$ female) and the overall mean \pm sD age was $44.0 \pm 7.7 \mathrm{yrs}$. Subjects had started working at 28.1 $\pm 3.2($ mean \pm sD) yrs of age. Hospital practice was the only form of employment for the majority $(88.1 \%)$ of constituted cases, who had mainly the postgraduate title of chest physician $(88.4 \%$; the others specialized in internal medicine or infectious diseases).

As many as 151 (25\%) admitted to being current smokers. Among the nonsmokers (454 (75\%)), $40.7 \%$ were never-smokers and $34.4 \%$ were exsmokers. The latter had given up smoking $11.4 \pm 6.8$ yrs earlier (mean \pm SD), with no differences between sexes. When stratified for age, the prevalence of smokers proved to be very high in the group of physicians aged $40-50$ yrs $(61.5 \%$ of smokers, $29.4 \%$ of the subjects of this age group). The prevalence of exsmokers was higher in the group aged $>50$ yrs $(48.9 \%$ of the sample in this age group), while neversmokers were prevalent in the group aged $<40$ yrs $(57.8 \%$ of this age group) $(\mathrm{p}<0.02)$.

Table 1. - Prevalence of smoking (percentage of total)

\begin{tabular}{lrrr}
\hline & \multicolumn{3}{c}{ Age yrs } \\
\cline { 2 - 4 } & \multicolumn{1}{c}{$<40$} & \multicolumn{1}{c}{$40-50$} & $>50$ \\
\hline Smokers & $36(18.7)$ & $88(29.4)$ & $19(21.1)$ \\
Exsmokers & $45(23.4)$ & $113(37.8)$ & $44(48.9)$ \\
Neversmokers & $111(57.8)$ & $98(32.8)$ & $27(30.0)$ \\
Total & $192(100)$ & $299(100)$ & $90(100)$ \\
\hline
\end{tabular}

$\mathrm{p}<0.02$.

\section{Attitudes towards tobacco smoking}

Regarding the second section of the questionnaire, some important differences emerged between current smokers and nonsmokers (table 2). It was found that a significantly $(p<0.001)$ higher proportion of smokers than nonsmokers believe that the dangers of smoking are currently overestimated and that air pollution damages health more than tobacco smoke. A similar difference was detectable in their opinions about passive smoking.

A still statistically significant difference, but to a lesser extent, was detected between smokers and nonsmokers in regard to the educational role of doctors. Smokers denied more frequently than nonsmokers that their general behaviour had an impact on patients. As for the personal compliance with rules, $30.3 \%$ of smokers admitted smoking in the inpatient clinic and $16.4 \%$ in the outpatient clinic.

Each chest physician was asked about making the next meeting of AIPO smoke free: $12.2 \%$ of responders disagreed with the idea of forbidding smoking at the meeting, with a significant difference between smokers (27\%) and nonsmokers $(7.2 \%)(\mathrm{p}<0.0001)$ and also between exsmokers $(11.3 \%)$ and neversmokers $(4.6 \%)(\mathrm{p}<0.009)$.

All age groups reported a lack of formal medical teaching about smoking. When asked about patient counselling on tobacco smoke, the participants answered that there was no type of counselling in $12.5 \%$ of cases and that it was not usual in $34.2 \%$ of cases. Passive smoking was judged not dangerous by $5 \%$ of responders, with a significant difference between smokers and nonsmokers $(\mathrm{p}<0.001)$ but not between high (FTQ score Š5) and low nicotine-addicted participants.

\section{Smokers-only section}

The overall prevalence of smokers was $25 \%$. No difference was detected between males and females, either in the overall prevalence or in the rate of heavy smokers. Among smokers, $66.7 \%$ smoked $<15$ cigarettes $\cdot$ day $^{-1}, 27.8 \%$ smoked 16-25 cigarettes.day ${ }^{-1}$ and 5.6\% smoked $>25$ cigarettes.day- ${ }^{-1}$. The nicotine content of preferred cigarettes showed a similar pattern: $50.7 \%$ of smokers among physicians smoked low-nicotine cigarettes, while $35.7 \%$ smoked medium, and $11.4 \%$ high-nicotine cigarettes. When a score of 5 was used as a cut-off, the Fagerstroem test suggested high addiction in $33.1 \%$ of smokers. These results did not match those for quantity and type (nicotine content) of daily cigarette consumption mentioned before and it is possible that the physicians substantially underestimated the burden of their personal smoking habit.

A majority $(59.4 \%)$ of smokers wanted to stop smoking, with more $(\mathrm{p}<0.001)$ of the high-addicted $(78.7 \%)$ than the low-addicted smokers $(49.5 \%)$. Among smokers, $64.8 \%$ believed it was possible to give up smoking successfully, with the low-addicted $(72.6 \%)$ believing more than the high-addicted $(48.9 \%, \mathrm{p}=0.005)$. The fear of body weight gain after cessation was felt by $43 \%$ of responders and this fear was stronger among highaddicted $(58.3 \%)$ than low-addicted smokers $(35.1 \%$, $\mathrm{p}<0.01)$.

When asked about personal compliance with the antismoking regulations in hospitals (a law against smoking in hospitals was issued in Italy in 1975), 16.4\% of smok- 
Table 2. - Attitudes and facts related to tobacco smoking (TS) as reported by Italian chest physicians

\begin{tabular}{lccc}
\hline & Current smokers $\%$ & Nonsmokers $\%$ & p-value \\
\hline Dangers of TS overestimated & 36 & 17 & $<0.001$ \\
TS less damaging than air pollution & 45.3 & 23.1 & $<0.001$ \\
Favourable to forbidding TS in all wards & 98.6 & 99.3 & NS \\
Passive TS is dangerous & 89.3 & 96.9 & $<0.001$ \\
Physician's lifestyle model for patients & 69.1 & 79.2 & $<0.05$ \\
Never taught about TS at university & 34.4 & 41.7 & Ns \\
\hline
\end{tabular}

ers admitted to smoking in outpatient clinics. There was a statistically significant difference between high-addicted $(29.2 \%)$ and low-addicted smokers $(10.2 \%, \mathrm{p}=0.01)$. Of the smokers, $30.3 \%$, admitted to smoking in hospital offices or in nurse offices and again there was a significant difference between high-addicted $(45.7 \%)$ and low-addicted smokers $(22.9 \%, \mathrm{p}<0.002)$.

\section{Nonsmokers-only section}

In the group of nonsmokers, there was a certain reluctance among nonsmokers to ask smokers to refrain from smoking. In fact, even if annoyed by environmental smoke in hospital, nonsmoking doctors asked their smoking colleagues to refrain in only $56.3 \%$ of cases. The reported compliance of smokers with this request was only $33.5 \%$. Complaint about colleagues' smoking was significantly more frequent among neversmokers $(83.6 \%)$ than among former smokers $(61.2 \%)(\mathrm{p}<0.001)$.

\section{Control for bias}

A total of 732 people collected the certificate of attendance, $178(24.3 \%)$ of whom declared themselves as current smokers. There was no significant difference between these data and the prevalence of smokers measured by the questionnaire.

\section{Discussion}

The sample tested here was thought to be representative of the whole population of Italian chest physicians. The number of those attending the meeting was almost onethird of the total number of members of the Italian Chest Physicians Society (AIPO). Since AIPO members are estimated to be the vast majority of Italian hospital chest physicians, there is no reason to assume self-selection between those attending the National Meeting of AIPO and non-attenders. A high percentage of the attenders answered the questionnaire $(61.5 \%)$ and, through independent assessment, it was shown that the percentage of smokers among responders was almost the same as that among all those attending the meeting.

To date, no national survey has been carried out on tobacco smoking among chest physicians. The present data seem to suggest that the prevalence of smoking among chest physicians has been considerably higher than for the general population over the past few years, based on the observation that the proportion of neversmokers is higher in the general population. If the prevalence of smoking in chest physicians was higher in the past, we can ask: is the smoking habit influenced by the physician's training or by their experience in respiratory medicine and frequent contact with tobacco-caused disease?

The prevalence of smokers in this sample was higher than that of northern European countries, Canada and the USA [13] and there seem to be no epidemiological reasons why the experience in chest medicine should be different in Italy from other European and non-European industrialized countries. Moreover, university training dealt little or not at all with the issue of tobacco smoking and related disease. It was also shown that the knowledge of tobacco-related health damage is not particularly good, especially among smoking physicians. Finally, the perception of a personal educational role towards the patients is low (and still lower in smokers). Hence, it can be concluded that medical training and clinical experience have little effect on the attitude towards smoking in Italian chest physicians.

Whatever the weight of medical experience, the main reason behind the prevalence of smokers among chest physicians seems to be a cohort effect. Smokers were concentrated in the cohort between 40 and 50 yrs $(61.5 \%$ of smokers). This is the group who attended high school and graduated between 1960 and 1980, i.e. when the smoking habit spread throughout Italy. During that period, knowledge about smoking-related damage to health among the general population was not widespread.

With this study, it was also confirmed that current smoking influences clinical practice. Current smokers continue to underestimate the effects of tobacco on health. A history of present or past smoking is associated with an overall underestimation of tobacco-related damage and a hesitant approach to smokers, whether patients or peers. Addicted smokers smoke more frequently than nonaddicted smokers on health premises. Data on the sale of nicotine replacement products confirm the lack of sensitivity to tobacco-related disease prevention among Italian doctors. In Italy during 12 months between 1994 and 1995, the total number of units (all types) sold in Italy was 293,000, while the figure in the UK (a country of almost the same population) amounted, for the same types, to $3,227,000$ [15].

The prevalence of smokers among the general population in Italy was, in 1994, approximately 32\% (38\% male and $26 \%$ female); during the same period the prevalence of smokers in Europe was 34\% (42\% males and 28\% females) [13]. Further, the percentage of Italians smoking $>25$ cigarettes $\cdot$ day $^{-1}$ decreased from $13 \%$ in 1992 to $8 \%$ in 1994 while, during the same period, in France this figure rose from 10 to $18 \%$.

In 1992, the percentage of neversmokers in Italy was $52 \%$. Moreover, during the 1980 s, the desire to stop smok- 
ing continued to increase even when the trend in other European countries was the opposite. From 1987 to 1989, the proportion of exsmokers among nonsmokers rose from $36 \%$ to $50 \%$ [14]. No statistics are available about the prevalence of smokers among the general population with the same educational level as physicians in Italy.

The prevalence of smoking among all Italian physicians is estimated to be around 28\% (32\% male and 24\% female) [12]. A previous sample of hospital physicians coming from different units showed an overall prevalence of $28.5 \%$ [7]. The present survey set the prevalence of smokers among chest physicians in Italy at approximately $25 \%$, with no differences between males and females. The lack of a difference between sexes, could be due to the small size of the sample of women, which was not sufficient to give strong statistical results. The percentage of successful quitters was found to be $34.4 \%$ and that of neversmokers $40.7 \%$.

In conclusion, the general attitude towards tobacco smoking in Italian chest physicians seems to be influenced more by the social attitudes concerning smoking than by formal medical training. Smoking is seen more as a social habit than as a risk factor for disease. Owing to incomplete training about tobacco and health and to current misunderstanding of the educational role of personal behaviour, Italian chest physicians do not fully comply with the rules against tobacco smoking in hospital. Smoking doctors, especially if addicted to nicotine, frequently smoke in hospital and do not counsel patients about smoking. According to the international official statement on "Smoking and health: a physician's responsibility" [16], physicians should play an active role in the control of smoking by participating in public debate regarding smoking, both individually and through medical organizations. Special effort is needed in the educational field concerning the issue of tobacco smoking for Italian chest physicians and a strong initiative towards smoke-free hospitals would help to spread the message. At present, nearly 50 hospital centres are committed to fighting for smoke-free hospitals.

Acknowledgements: The authors wish to thank the Scientific Committee on Tobacco and Health of the International Union against Tuberculosis and Lung Disease (Paris) and R. Masironi of the International Network Towards Smoke Free Hospitals (Geneva) for their invaluable assistance.

\section{References}

1. International Agency for Research on Cancer. Monograph on the evaluation of the carcinogenic risk of chemical to human, Vol. 38, Tobacco smoking. Lyon, IARC, 1986.

2. Office of the US Surgeon General. Reducing the health consequences of smoking: 25 years of progress. Centers for Disease Control Publication No. 89-8411, 1989.

3. Office of Health and Environmental Assessment. Respiratory health effects of passive smoking: lung cancer and other disorders. Washington DC, US Environmental Protection Agency, 1992.

4. Peto R, Lopez AD, Boreham J, Thun M, Heath C. Mortality from tobacco in developed countries: indirect estimation from national vital statistics. Lancet 1992; 339: $1268-1278$.

5. Peto R, Lopez AD, Boreham J, Thun M, Heath C Jr. Mortality from smoking in developed countries. Oxford, Oxford University Press, 1994.

6. La Vecchia C, Negri E, Decarli A, Fasoli M, Cislaghi C. Cancer mortality in Italy: an overview of age specific and age standardised trends from 1955 to 1984 . Tumori 1990; 76: 87-166.

7. Nardini S, Purro A, Lusuardi M, Mandro M, Donner CF. Italian chest physicians and tobacco smoke: a survey. Tubercle Lung Dis 1994; 46: Suppl. 1, 111.

8. Nardini S, Bertoletti R, Rastelli V, Ravelli L. Tobacco smoke and hospital physicians: can addiction influence practice? Eur Respir J 1995; 8: Suppl. 19, 51s.

9. Masironi R. Proceedings of the International Meeting on Tobacco Smoke and Health Staff, Venice, May 30-31, 1989.

10. Arciti C, Persici P, Pistone M, et al. A report on the status of tobacco smoking among the health professionals in Italy. 9e Conference Mondiale sur le tabac et la santé, Paris, October 10-14, 1994. Int J Smok Cess 1994; 3: 1014.

11. Fagerstroem KO, Schneider NG. Measuring nicotine dependence: a review of the Fagerstroem Tolerance Questionnaire. J Behav Med 1989; 12: 159-182.

12. Arciti C, Mereu C, Barbieri A, Marcello L, Santi L. Italian league against cancer: smoking habits among personnel in Italy. Eur Respir J 1995; 8: Suppl. 19, 51 s.

13. Commission of the European Community. Eurobarometer Survey, 1987/1994. Brussels, INRA, 1995.

14. Commission de la Communite Européenne, Direction General V/F12 Employe Relations Industrielle Affaires Sociales. Brussels, Les Européens et la Santé Publique, 43 0/NRA (Europ) European Coordination Office, 1995; p. 17.

15. Masironi R. The smoking habits of European doctor; new insights, Future Directions in Nicotine Replacement Therapy, Paris, European Medical Association on Smoking and Health, Chester, ADIS International, 1994; pp. 4147.

16. American College of Chest Physicians; American Thoracic Society; Asia Pacific Society of Respirology: Canadian Thoracic Society; European Respiratory Society; International Union Against Tuberculosis and Lung Disease Smoking and health: a physician's responsability. A statement of the joint committee on smoking and health. Eur Respir J 1995; 8: 1808-1811. 